\title{
Peripapillary and Macular Choroidal Vascularity Index in Eyes with Fuchs' Uveitis
}

yasemin ozdamar erol ( $\square$ yasemin_oz@yahoo.com )

Ulucanlar Eye Training and Research Hospital https://orcid.org/0000-0002-0406-8921

Anıl Güngör

SBU Ulucanlar Goz Egitim Ve Arastirma Hastanesi

\section{Berrak Şekeryapan Gediz}

SBU Ulucanlar Goz Egitim Ve Arastirma Hastanesi

\section{Research Article}

Keywords: Fuchs Uveitis, Choroidal Vascularity Alteration, Fovea, Peripapillary Area, Inflammation

Posted Date: July 29th, 2021

DOI: https://doi.org/10.21203/rs.3.rs-749309/v1

License: (1) This work is licensed under a Creative Commons Attribution 4.0 International License. Read Full License 


\section{Abstract \\ Background}

To investigate the choroidal vascularity alterations of macula and peripapillary area in eyes with unilateral Fuchs uveitis (FU).

\section{Methods}

This study included 18 eyes with unilateral FU and 18 healthy fellow eyes. The choroidal vascularity index $(\mathrm{CVI})$ was analyzed and the results were compared between eyes with FU and healthy fellow eyes (control group).

\section{Results}

The mean subfoveal (s)CVI (\%) value was significantly lower in the FU group as compared with the control group: $60.92 \pm 2.63$ vs. $64.01 \pm 2.54$, respectively $(p=0.001)$. The mean $p C V I(\%)$ values of superior and inferior quadrant were significantly lower in the Fuchs group as compared with the control group:58.87 \pm 4.48 vs. $61.98 \pm 3.32$, respectively, in superior quadrant $(p=0.035)$; and $57.29 \pm 6.65$ vs. $61.44 \pm 4.76$, respectively, in inferior quadrant $(p=0.014)$.

\section{Conclusion}

The chronic continuous inflammation in FU causes inflammation-mediated thinning in the vascular area of the subfoveal and peripapillary choroid. The changes in the peripapillary region are remarkable in terms of the further glaucoma risk of these eyes.

\section{Introduction}

Fuchs' uveitis (FU) is mainly unilateral, low-grade, chronic inflammation of anterior uvea. The prevalence of FU in Turkey has been reported as $6.3 \%{ }^{(1,2,3)}$. Although the etiology of FU remains controversial, it has been suggested that immunological and infectious causes may be responsible for triggering inflammation in recent studies. ${ }^{(3,5-8)}$

The chronic inflammation causes characteristic anterior segment findings, including diffusely spread medium and/or stellate keratic precipitates (KPs), diffuse atrophy of iris stroma with or without heterochromia, low-grade anterior chamber reaction $(9,10)$. In addition, this inflammation affects posterior segment and; in eyes with FU the most frequent findings of posterior involvement are cells- opacities in the anterior vitreous ${ }^{(11-13)}$. 
In eyes with $\mathrm{FU}$, the influence of choroideal layer has been demonstrated by imaging methods in recent studies ${ }^{(14-17)}$. Studies by using enhanced deep imaging-optic cohorence tomography (edi-OCT) have been reported decreased choroidal thickness (CT) in eyes with FU ${ }^{(15-17)}$. Edi-OCT has informed choroidal thickness but, it has no a true standard regarding the vascular supply because of including the stromal and interstitial layer of choroid. The choroidal vascularity index (CVI) is a new choroidal imaging method first described by Agrawal et al. ${ }^{(18)}$. CVI provides more reliable data of the choroidal vascular status. Using image binarization method, the choroid can be divided into a stromal area (SA) and a luminal area (LA), and CVI has been determined as the ratio of LA to total choroidal area. Researches on macula CVI have been increasing significantly especially in various retinal and choroidal diseases ${ }^{(19-21)}$. Also, FU has an increased risk of glaucoma as well as being an uveal inflammation of intermediate area $(3,22)$. Hence, assessment of the peripapillary choroidal vascularity should be evaluated well. Based on these ideas, the present study analyezed submacular and peripapillary CVI, LA and SA in eyes with unilateral FU and the measurements were compared healthy fellow eyes.

\section{Material And Methods}

A total of 18 eyes of 18 patients with unilateral FU and 18 fellow eyes of these patients were included in this study. The study protocol was approved by the Ethics Committee of the hospital and was conducted in accordance with the Declaration of Helsinki.

The diagnostic criteria of FU included diffusely and/or local spread medium and/or stellate KPs, chronic low-grade anterior chamber reaction, iris atrophy accompanied or not with heterochromia, varying degrees of vitreous cell and fibril-like vitreous appearance ${ }^{(13)}$.

Patients with at least 6 months follow-up were included in this study. Exclusion criteria were as followed;

- Patients with any associated retinal/ optic disc pathology,

- eyes with spherical equivalent beyond -3 and +1.5 D,

- patients with the history of systemic disease

- use of systemic medication,

- $\geq 2$ anterior uveitis attacks in the last 6 months,

- eyes with corneal abnormality ,

- history of topical treatment in the last 6 months

- Eyes with more than 1 anterior chamber reaction

All patients underwent a complete ophthalmic examination in both eyes. Intraocular pressure was measured Goldman Applanation tonometry. All eyes were phakic. The assesment of glaucoma were performed using peripapillary RNFL analyses and perimetry and none of the eyes had glaucoma.

\section{Choroidal imaging analysis}


For CT and CVI measurements, choroidal imaging was performed using the EDI mode of the SD-OCT (Heidelberg Engineering $\mathrm{GmbH}$, Heidelberg, Germany), which automatically reinverts the inverted images and enables EDI-OCT images to be captured directly. Subfoveal CT (SCT) was measured manually from the outer border of the retinal pigment epithelium to the inner scleral border at the subfoveal region with EDI mode. Peripapillary CT (pCT) in the superior, nasal, inferior and temporal quadrants was measured at $1 \mathrm{~mm}$ from the optic disc border by using a vertical EDI-OCT scan and a horizontal EDI-OCT scan closest to the optic nerve head center.

For CVI measurements, EDI-OCT images were binarized using the method described by Agrawal et al. Niblack's auto-local threshold tool was applied to allow demarcation of the luminal area and the stromal area. The images were then converted back to an RGB (red, green, blue) image, and the luminal area was determined using the colour threshold tool. CVI, was defined as the proportion of luminal area (LA) to the total choroidal area (TCA). The submacular CVI (sCVI) was measured in central $1500 \mu \mathrm{m}$ on horizontal EDI-OCT scan. The peripapillary CVI (pCVI) was measured separately in superior, temporal, nasal, and inferior quadrants ( $1000 \mu \mathrm{m}$ width on four sides from the optic disc border) of the peripapillary area on horizontal and vertical EDI-OCT scans. The stromal area (SA) was calculated by subtracting the LA from the TCA. The ratio of the LA to the SA (LSR) was calculated. All measurements were performed for both eyes by two investigators (BSG, YOE) who were blind to subject's disease status. To minimize the effect of circadian variation on choroidal circulation, all CT measurements were performed at the same time of day (between 10 a.m. and 12 p.m.).

\section{Statistical analysis}

Statistical analysis was performed using IBM SPSS Statistics 17.0 software (IBM Corporation, Armonk, NY, USA). The variables are presented as mean \pm standard deviation and minimum-maximum. Paired ttest was used to test the differences between both eyes of patients with FU. Relationship between continuous variables was analyzed with the Spearman correlation test. A p-value of less than 0.05 was considered as statistically significant.

\section{Results}

The study included 18 patients with unilateral FU including 11 males (61.1\%) and 7 females (38.9\%). The mean age was $34.8 \pm 9.6$. There were diffusely spread keratic precipitates (KPs)[ (medium sized in 15 (83.3\%) eyes, stellate-medium in $3(\mathbf{1 6 . 7 \% )}$ ) eyes )]. In all eyes, there was vitreous infiltration of varying grades $(100 \%)$. All eyes had phakic.

The mean SCT was thinner in the Fuchs group as compared with the control group: $372.41 \pm 90.01 \mu \mathrm{m}$ vs. $381.41 \pm 80.91 \mu \mathrm{m}$, however the difference was not significant (p囚0.05) (Table 1). 
Table 1

Subfoveal choroidal thickness and peripapillary choroidal thickness values in study groups.

\begin{tabular}{|llll|}
\hline & $\begin{array}{l}\text { Fuchs group } \\
\text { mean } \pm \text { SD (min-max) }\end{array}$ & $\begin{array}{l}\text { Control group } \\
\text { mean } \pm \text { SD (min-max })\end{array}$ & p value $^{1}$ \\
\hline SCT $(\mu \mathrm{m})$ & $372.41 \pm 90.01(201-549)$ & $381.41 \pm 80.91(232-512)$ & $>0.05$ \\
\hline pCT $(\mu \mathrm{m})$ & & & \\
\hline Temporal & $239.79 \pm 83.54(85-384)$ & $266.64 \pm 80.35(179-458)$ & $>0.05$ \\
\hline Nasal & $238.14 \pm 100.11(124-467)$ & $262.64 \pm 118.10(153-560)$ & $>0.05$ \\
\hline Superior & $235.36 \pm 90.34(70-446)$ & $246.29 \pm 90.10(139-452)$ & $>0.05$ \\
\hline Inferior & $189.57 \pm 67.36(105-334)$ & $215.71 \pm 104.20(98-459)$ & $>0.05$ \\
\hline sCT: Subfoveal choroidal thickness, pCT: Peripapillary choroidal thickness, & \\
\hline 1 paired t test & & & \\
\hline
\end{tabular}

The mean pCT was thinner in the Fuchs group in all quadrants as compared with the control group: $239.79 \pm 83.54 \mu \mathrm{m}$ vs. $266.64 \pm 80.35 \mu \mathrm{m}$, respectively, in temporal quadrant; $238.14 \pm 100.11 \mu \mathrm{m}$ vs. $262.64 \pm 118.10 \mu \mathrm{m}$, respectively, in nasal quadrant; $235.36 \pm 90.34 \mu \mathrm{m}$ vs. $246.29 \pm 90.10 \mu \mathrm{m}$, respectively, in superior quadrant; and $189.57 \pm 67.36 \mu \mathrm{m}$ vs. $215.71 \pm 104.20 \mu \mathrm{m}$, respectively, in inferior quadrant. However the difference between groups for all quadrants were not significant ( $p \otimes 0.05$, all values) (Table 1).

Table 2 shows the choroidal vascular measurements of the submacular and peripapillary regions among the groups (Figs. 1 and 2). The mean SCVI (\%) value was significantly lower in the Fuchs group as compared with the control group: $60.92 \pm 2.63$ vs. $64.01 \pm 2.54$, respectively $(p=0.001)$. The mean sLA was significantly lower in FU group $(0.90 \pm 0.14(0.62-1.14)$ than the control group $(0.97 \pm 0.15(0.63-$ 1.17) (p:0.045) and also, there was statistically significance in respect of LSR between the FU $(1.57 \pm 0.17$ ) and control groups $(1.79 \pm 0.20)$ (p:0.001). 
Table 2

Choroidal vascular values of the subfoveal and peripapillary areas

Fuchs group

mean $\pm S D(\min -\max )$
Control group

mean $\pm S D(\min -\max )$

p value $^{1}$

\section{Subfoveal}

\begin{tabular}{llll} 
TCA $\left(\mathrm{mm}^{2}\right)$ & $1.49 \pm 0.25(1.10-2.00)$ & $1.52 \pm 0.23(1.05-1.89)$ & 0.501 \\
\hline LA $\left(\mathrm{mm}^{2}\right)$ & $0.90 \pm 0.14(0.62-1.14)$ & $0.97 \pm 0.15(0.63-1.17)$ & 0.045 \\
SA $\left(\mathrm{mm}^{2}\right)$ & $0.58 \pm 0.12(0.42-0.85)$ & $0.55 \pm 0.09(0.39-0.74)$ & 0.194 \\
CVI $(\%)$ & $60.92 \pm 2.63(56.80-66.40)$ & $64.01 \pm 2.54(60.39-68.69)$ & 0.001 \\
LSR & $1.57 \pm 0.17(1.31-1.97)$ & $1.79 \pm 0.20(1.52-2.19)$ & 0.001
\end{tabular}

\section{Peripapillary}

Temporal

$\begin{array}{llll}\text { TCA }\left(\mathrm{mm}^{2}\right) & 0.60 \pm 0.16(0.26-0.88) & 0.62 \pm 0.13(0.45-0.92) & 0.696 \\ \text { LA }\left(\mathrm{mm}^{2}\right) & 0.36 \pm 0.11(0.13-0.56) & 0.39 \pm 0.10(0.27-0.62) & 0.465 \\ \text { SA }\left(\mathrm{mm}^{2}\right) & 0.23 \pm 0.06(0.12-0.32) & 0.23 \pm 0.03(0.18-0.30) & 0.731 \\ \text { CVI }(\%) & 59.90 \pm 3.59(52.87-65.61) & 62.21 \pm 3.52(55.32-68.38) & 0.075 \\ \text { LSR } & 1.51 \pm 0.22(1.12-1.90) & 1.66 \pm 0.25(1.23-2.16) & 0.071\end{array}$

Nasal

$\begin{array}{llll}\text { TCA }\left(\mathrm{mm}^{2}\right) & 0.54 \pm 0.15(0.31-0.84) & 0.58 \pm 0.11(0.41-0.78) & 0.440\end{array}$

$\begin{array}{llll}\mathrm{LA}\left(\mathrm{mm}^{2}\right) & 0.32 \pm 0.11(0.13-0.55) & 0.34 \pm 0.09(0.22-0.55) & 0.433\end{array}$

$\begin{array}{llll}\mathrm{SA}\left(\mathrm{mm}^{2}\right) & 0.22 \pm 0.03(0.16-0.29) & 0.23 \pm 0.03(0.16-0.28) & 0.578\end{array}$

$\begin{array}{llll}\text { CVI (\%) } & 57.33 \pm 6.04(44.23-66.03) & 59.29 \pm 5.61(51.63-70.19) & 0.295\end{array}$

$\begin{array}{llll}\text { LSR } & 1.38 \pm 0.33(0.79-1.94) & 1.50 \pm 0.39(1.06-2.35) & 0.306\end{array}$

Superior

\begin{tabular}{llll} 
TCA $\left(\mathrm{mm}^{2}\right)$ & $0.58 \pm 0.11(0.36-0.74)$ & $0.62 \pm 0.12(0.38-0.80)$ & 0.088 \\
\hline LA $\left(\mathrm{mm}^{2}\right)$ & $0.34 \pm 0.07(0.20-0.47)$ & $0.38 \pm 0.08(0.23-0.54)$ & 0.026 \\
$\mathrm{SA}\left(\mathrm{mm}^{2}\right)$ & $0.23 \pm 0.04(0.16-0.32)$ & $0.23 \pm 0.04(0.15-0.30)$ & 0.737 \\
CVI $(\%)$ & $58.87 \pm 4.48(50.67-66.92)$ & $61.98 \pm 3.32(58.26-68.88)$ & 0.035
\end{tabular}




\begin{tabular}{|llll|}
\hline & $\begin{array}{l}\text { Fuchs group } \\
\text { mean } \pm \text { SD (min-max) }\end{array}$ & $\begin{array}{l}\text { Control group } \\
\text { mean } \pm \text { SD (min-max) }\end{array}$ & p value \\
\hline LSR & $1.45 \pm 0.27(1.02-2.02)$ & $1.65 \pm 0.25(1.39-2.21)$ & 0.058 \\
\hline Inferior & & & \\
\hline TCA $\left(\mathrm{mm}^{2}\right)$ & $0.49 \pm 0.12(0.29-0.78)$ & $0.52 \pm 0.15(0.36-0.86)$ & 0.379 \\
\hline LA $\left(\mathrm{mm}^{2}\right)$ & $0.28 \pm 0.10(0.14-0.49)$ & $0.32 \pm 0.10(0.20-0.55)$ & 0.130 \\
\hline SA $\left(\mathrm{mm}^{2}\right)$ & $0.20 \pm 0.04(0.13-0.29)$ & $0.19 \pm 0.05(0.14-0.30)$ & 0.476 \\
\hline $\mathrm{CVI}(\%)$ & $57.29 \pm 6.65(49.32-70.82)$ & $61.44 \pm 4.76(53.72-68.65)$ & 0.014 \\
\hline LSR & $1.40 \pm 0.44(0.97-2.42)$ & $1.63 \pm 0.32(1.16-2.19)$ & 0.043 \\
\hline $\begin{array}{l}\text { TCA: total choroidal area, LA: luminal area, SA:stromal area, CVI: choroidal vascularity index, LSR: } \\
\text { luminal-to-stromal ratio }\end{array}$ & & \\
\hline 1 paired t test & & & \\
\hline
\end{tabular}

The mean pCVI (\%) values were lower in the Fuchs group in all quadrants as compared with the control group, however the difference between the superior and inferior quadrants were significant: $59.90 \pm 3.59$ vs. $62.21 \pm 3.52$, respectively, in temporal quadrant (p囚0.05); $57.33 \pm 6.04$ vs. $59.29 \pm 5.61$, respectively, in nasal quadrant ( $\mathrm{p} \otimes 0.05) ; 58.87 \pm 4.48$ vs. $61.98 \pm 3.32$, respectively, in superior quadrant $(p=0.035)$; and $57.29 \pm 6.65$ vs. $61.44 \pm 4.76$, respectively, in inferior quadrant $(p=0.014)$.

There was a statistically significant difference between FU groups $(0.34 \pm 0.07)$ and control groups $(0.38$ \pm 0.08 ) in terms of superior quadrant LA (p:0.026). In addition, LSR of superior quadrant was lower in the FU group $(1.45 \pm 0.27)$ than the control group $(1.65 \pm 0.25)$ but the differenence was not significant (p:0.058).

The correlation analysis revealed a moderate and positive significant correlation between superior and inferior $\mathrm{PCVI}(r=0.574, p=0.032)$. In addition, in majority of patients with decrease in subfoveal CVI, concomitant increase was noted in inferior PCVI (97\%) and superior PCVI $(100 \%)$, while a decrease in inferior pCVI was observed in $92.3 \%$ of the patients with decrease in superior $\mathrm{pCVI}$.

\section{Discussion}

The many pathogenetic mechanisms of FU have been proposed that an unknown process is responsible for abnormal destruction of uveal pigment and low-grade inflammation. Iris stromal atrophy and infiltration of the iris stroma and ciliary body with lymphocytes and plasma cells have been shown as the most characteristic pathologic features in eyes with $\mathrm{FU}(23,24)$. Until now, anterior segment findings of $\mathrm{FU}$ have been extensively described. In our previous article, we have reported the posterior segment findings 
in detail and especially all eyes had vitreous involvement ${ }^{(13)}$. The regarding posterior segment involvement have been explained with different theories, such as the direct spread of inflammation and a secondary response to inflammation in eyes with $\mathrm{FU}(24,25)$.

The choroid has an unique anatomical structure that can easily be affected by systemic or ocular inflammatory conditions and many researchs concerning choroidal imaging methods have been reported in ocular diseases ${ }^{(26)}$. Edi-OCT is the most used of these analyzes and measures the entire choroidal thickness both stromally and interstitially. CVI is a new choroidal imaging method and it provides better detailed data of the choroidal vascular status $(18,19)$.

The effects of acute and chronic inflammation on CT differ in uveitic disease (27-33). The measurement of CT has been increased in acute exacerbations of the disease in cases such as $\mathrm{VKH}$, SO, posterior scleritis tha the choroidal layer is primarily involved ${ }^{(33)}$. However, the variation of CT has been reported in uveitic disease without direct choroidal involvement ${ }^{(27-32)}$.

Past studies on HLA-B27-associated uveitis cases without primary posterior segment involvement revealed an increase in $\mathrm{CT}$ in the acute phase of the disease and also a regression in the thickness by treatment. Increased CT observed in acute ocular inflammatory conditions including anterior uveitis and/or posterior uveitis involvement and without direct involvement of the choroidal layer, is explained by the inflammation-dependent increased choroidal blood flow or immunological mechanisms ${ }^{(30-32)}$. The reduction in $\mathrm{CT}$ in chronic uveitic cases has been suggested to be associated with ischemic changes related to chronicity, fibrosis and decreased vascular component $(33,34)$.

In FU, chronic-persistent inflammation in the intermediate area and several mediators released in the environment are considered to eventually interact with the choroidal layer. The decline in CT was demonstrated in the studies on FU and CT (15-17). In a study on CT measurement from foveal and extrafoveal areas in 9 eyes with unilateral FU and the unaffected eyes, authors reported a significant diffuse choroidal thinning in eyes with $\mathrm{FU}^{(15)}$. In a study by Balcl et al. the CT was reported to be significantly lower in 15 eyes with unilateral FU as compared with the 20 control eyes and the unaffected eyes of patients ${ }^{(16)}$. In a study by Kardeş et al., the measurements of CT by edi-OCT in 25 eyes of patients with unilateral involvement were compared with the their healthy eyes and the CT was found to be significantly decreased in eyes with FU when compared to healthy eyes $(296.47 \pm 32.29 \mu \mathrm{m}$ vs. 324.47 $\pm 26.73 \mu \mathrm{m} ; \mathrm{p}=0.001$ ) along with a significant thinning in ganglion cell layer in eyes with FU ${ }^{(17)}$. In these studies, thinning in the choroidal layer has been suggested to be linked to the presence of a chronic inflammation or the consideration of choroidal layer as a continuation of the uveal tissue ${ }^{(15-17)}$. Our findings also revealed a reduction in CT in the submacular area in eyes with FU when compared to the unaffected eyes. There was also no difference between the eyes' retinal thickness measurements in the macular area. This seems to indicate that persistent inflammation in FU eyes affects the choroidal layer due to its anatomical structure, whereas the retinal layers are not affected. 
Vascular effects in the choroidal layer are evaluated indirectly in CVI measurements. CVI can potentially serve as a marker for disease activity and can be used to monitor remission during the follow-up of uveitic diseases. A decrease in $\mathrm{CVI}$ and an increase in CT were found in a study conducted on eyes with recurrent anterior uveitis in patients with $\mathrm{VKH}$, in which the choroidal stroma was directly involved, and it was reported that the decrease in CVI was due to active infiltration of the choroidal stroma and compression on the vascular area due to edema ${ }^{(35)}$. In an acute anterior uveitis exacerbation in HLA-B27associated uveitic eyes without direct choroidal involvement, an increase in both choroidal thickness and CVI measurement due to choroidal vascular enlargement has been reported ${ }^{(32)}$.

There is no direct choroidal involvement in FU. However, decrease in CT was reported in both the aforementioned studies ${ }^{(15-17)}$ as well as in the current study. In our study, the submacular CVI measurements revealed a significant decrease in eyes with FU compared to healthy eyes.

In addition, a significant decrease was observed in the submacular area in the evaluation of LA and luminal-stromal area ratio. This reveals that the continuous chronic inflammation in FU causes inflammation-mediated thinning in the vascular area of the choroid, even if it is not a uveitic disease directly involving the choroidal structures. This thinning in CVI and LA measurements has emerged as an evidence of affected choroidal layer. In the literature review, in a study in which submacular CVI was measured, it was found that the submacular CVI measurement of 39 unilateral FU eyes was lower than the other healthy eyes and the control group (24 eyes) ${ }^{(36)}$.

The choroid layer has a very different anatomical structure from the retinal layer. The choroidal circulation is a high-flow system with a structure allowing the transfer of metabolites and mediators in the choroid and surrounding tissues. Therefore, as shown in the aforementioned studies in anterior uveitic eyes and also in our study, it is easily affected by inflammatory processes even those not directly affecting itself. These results show us clearly that this involvement in the choroidal layer is secondary to inflammation rather than uveal tissue continuity or direct involvement.

FU causes significant thinning in the iris stroma layer and ciliary body ${ }^{23,24)}$. However, no change in the SA measurements in the choroidal layer found in our study may be another explanation for the choroid not being affected directly. Also, the reduction in the thickness of the choroidal layer in our study occurs as a result of the decrease in the LA. LA involvement is thought to be due to changes in the vascular system resulting from chronic inflammation.

Another region evaluated in our study is the peripapillary area. The peripapillary area has a unique importance in terms of both anatomical and functional structure. The blood supply to the surface nerve fiber layer and prelaminar part of the optic nerve head is provided by the peripapillary choroidal vessels (37). The analysis of peripapillary choroidal vascularity may be helpful in evaluating optic nerve head blood flow. Glaucoma and ocular hypertension have been reported as common complications of FU in several reports ${ }^{(38,39)}$. It is known that FU has an increased risk of glaucoma for reasons abnormal angle vessels, obstruction of trabecular meshwork by inflammatory cells, disruption of uveal and 
juxtacanalicular structures, trabecular meshwork fibrosis and steroid-induced ocular hypertension $(22,40)$. Therefore vascular support of peripapillary area should be well evaluated in these eyes. In a study conducted with optic coherence tomography angiography, it was found that radial peripapillary capillary vessel density was lower in 34 unilateral FU eyes without glaucomatous signs compared to other healthy eyes and control eyes (37 eyes), and chronic inflammation in FU has led to impaired blood flow at the optic nerve head ${ }^{(39)}$.. Our study is the first investigation evaluating the choroidal vascular changes in the peripapillary region in eyes with FU. In the peripapillary CVI evaluation, a decrease was detected in all quadrants compared to the healthy eye, but the decrease in superior and inferior were significant. In addition, the decrease in LA in all quadrants in the peripapillary area is remarkable and the decrease in the superior area was found to be statistically significant. This shows us that peripapillary choroidal blood flow is impaired in these eyes without glaucoma, and the sensitivity of these eyes to glaucoma may be even more pronounced. The observation of changes and involvement of CVI and LA detected in the macular area also in the peripapillary area demonstrates the likelihood of effects via similar mechanisms. In addition, the correlation between the decrease in submacular CVI and the peripapillary sup-inf CVI demonstrates that the parallel and prominent involvement of several areas of the choroid layer anatomically. Albeit not statistically significant, peripapillary CT findings in our study indicate thinning in all quadrants compared to healthy eyes. This may indicate the likelihood of being affected secondary to chronic inflammation as in the submacular CT.

The only disadvantage of our study is the lack of data on duration of uveitis history in patients. Since the eyes with FU are usually asymptomatic, it is difficult to determine this course precisely.

As a result, a structurally and functionally healthy choroidal vasculature plays an essential role in the normal function of the macula and peripapillary region. In eyes with FU, especially the changes in the peripapillary area are remarkable as these eyes are prone to glaucoma. The examination of choroidal vascular changes offers a novel explanation to the pathological involvement of choroid in FU.

\section{Declarations}

\section{Acknowledgements}

This research received no specific grant from any funding agency in the public, commercial, or not-forprofit sectors.

\section{Conflict of Interest}

The authors report no conflicts of interest and have no proprietary interest in any of the materials mentioned in this article. All authors have contributed significantly, and all authors are in agreement with the content of the manuscript.

\section{References}


1. Hovakimyan A, Baglivo E, Cunningham ET Jr (2010) Fuchs Uveitis Syndrome in the developing world. Int Ophthalmol Clin 50(2):145-153

2. Yalçındağ FN, Özdal PC, Özyazgan Y, Batıoğlu F, Tugal-Tutkun I, BUST Study Group (2018) Demographic and Clinical Characteristics of Uveitis in Turkey: The First National Registry Report. Ocul Immunol Inflamm 26(1):17-26

3. Sun Y, Ji Y (2019) A literature review on Fuchs uveitis syndrome: an update. Surv Ophthalmol. Oct 14. pii: S0039-6257(19)30282-6. doi10.1016/j. survophthal.2019.10.003

4. Quentin CD, Reiber $H$ (2004) Fuchs heterochromic cyclitis:rubella virus antibodies and genome in aqueous humor. Am J Ophthalmol 138:46-54

5. Barequet IS, Li Q, Wang Y, O'Brien TP, Hooks JJ, Stark WJ (2000) Herpes simplex virus DNA identification from aqueous fluid in Fuchs heterochromic iridocyclitis. Am J Ophthalmol 129:672673

6. Schwab IR (1991) The Epidemiologic Association of Fuchs' Heterochromie Iridocyclitis and Ocular Toxoplasmosis. Am J Ophthalmol 111:356-362

7. Chan NS, Chee SP, Caspers LB (2018) B. Clinical Features of CMV-Associated Anterior Uveitis. Ocul Immunol Inflamm 26:107-115

8. Norrsell K, Sjödell L (2008) Fuchs' heterochromic uveitis: a longitudinal clinical study. Acta Ophthalmol 86(1):58-64

9. Tugal-Tutkun I, Güney-Tefekli E, Kamaci-Duman F, Corum I (2009) A cross-sectional and longitudinal study of Fuchs uveitis syndrome in Turkish patients. Am J Ophthalmol 148(4):510-515

10. Mohamed Q, Zamir E (2005) Update on Fuchs' uveitis syndrome. Curr Opin Ophthalmol 16(6):356363

11. Bouchenaki N, Herbort CP (2010) Fluorescein angiographic findings and clinical features in Fuchs' uveitis. Int Ophthalmol 30:511-519

12. Zarei M, Darabeigi S, Mehrpour M, Roohipoor R, Ghassemi H, Ebrahimiadib N (2019) Fuchs' Uveitis in Iranian Patients: A Review of 89 Eyes. Ocul Immunol Inflamm 27:1077-1085

13. Özdamar Erol YMD, İnanç MMD, Özdal PMD (2020) Fuchs' Uveitis: Is It Different from What We Know? Ocul Immunol Inflamm. Aug 24:1-6. doi: 10.1080/09273948.2020.1795207

14. Przybyś M, Brydak-Godowska J, Kęcik D. Subfoveal Choroidal Thickness and Its Intereye Differences in Fuchs Uveitis Syndrome Evaluated Using Optical Coherent Tomography. Ocul Immunol Inflamm. 2020 Jan 16:1-6. doi: 10.1080/09273948.2019.1699579

15. .Cerquaglia A, laccheri B, Fiore T, Lupidi M, Torroni G, Fruttini D, Giacalone C, Cagini C (2016) Fullthickness choroidal thinning as a feature of Fuchs Uveitis Syndrome: quantitative evaluation of the choroid by Enhanced Depth Imaging Optical Coherence Tomography in a cohort of consecutive patients. Graefes Arch Clin Exp Ophthalmol 254(10):2025-2031

16. Balci O, Ozsutcu M (2016) Evaluation of Retinal and Choroidal Thickness in Fuchs' Uveitis Syndrome. J Ophthalmol 2016:1657078 
17. Kardes E, Sezgin Akçay BI, Unlu C, Ergin A (2017) Choroidal Thickness in Eyes with Fuchs Uveitis Syndrome. Ocul Immunol Inflamm 25(2):259-266

18. Agrawal R, Salman M, Tan KA, Karampelas M, Sim DA, Keane PA, Pavesio C (2016) Choroidal Vascularity Index (CVI)--A Novel Optical Coherence Tomography Parameter for Monitoring Patients with Panuveitis? PLoS One 11(1):e0146344 11(

19. Betzler BK, Ding J, Wei X, Lee JM, Grewal DS, Fekrat S, Sadda SR, Zarbin MA, Agarwal A, Gupta V, Schmetterer L, Agrawal R (2021 Jan) Choroidal vascularity index: a step towards software as a medical device. $\mathrm{Br} \mathrm{J}$ Ophthalmol 29:bjophthalmol-2021

20. Kim ry, Chung DH, Kim M, Park YH (2020) Use of choroidal vascularity index for choroidal structural evaluation in central serous chorioretinopathy with choroidal neovascularization. Retina 40(7):13951402

21. Pellegrini $M$, Veronese $C$, Bernabei F, Lupidi $M$, Cerquaglia A, Invernizzi A, Zicarelli F, Cimino L, Bolletta E, Vagge A, Ciardella AP (2021) Choroidal Vascular Changes in Multiple Evanescent White Dot Syndrome. Ocul Immunol Inflamm 17(2):340-345 29(

22. Toniolo JT, Hall AJ, Smith JG, Levy J, Lim LL (2017) Risk Factors for Glaucoma in a Cohort of Patients with Fuchs Heterochromic Iridocyclitis. Ocul Immunol Inflamm 25(6):753-759

23. Rivir-Rallatos C (2002) Fuchs' Heterochromic Iridocylitis. In: Diagnosis and Treatment of Uveitis [1 ed.] (Ed) Foster CS, Vitale AT. Saunders, USA, pp 693-700

24. Rutzen AR, Raizman MB. Fuchs' Heterochromic Iridocyclitis. In; Albert \& Jakobiec's principles and practice of ophthalmology. (Eds.) Albert DM, Jakobiec FA, Miller JW. Philadelphia, PA; Edinburgh. pg: 1231-1243, Saunders/Elsevier

25. Kreps EO, Derveaux T, De Keyser F, Kestelyn P (2016) Fuchs' Uveitis Syndrome: No Longer a Syndrome? Ocul Immunol Inflamm 24(3):348-357

26. Singh SR, Vupparaboina KK, Goud A, Dansingani KK, Chhablani J (2019) Choroidal imaging biomarkers. Surv Ophthalmol 64(3):312-333

27. Kim M, Kim H, Kwon HJ, Kim SS, Koh HJ, Lee SC (2013) Choroidal thickness in Behcet's uveitis: an enhanced depth imaging-optical coherence tomography and its association with angiographic changes. Invest Ophthalmol Vis Sci 5(9):6033-6039 54(

28. Ishikawa S, Taguchi M, Muraoka T, Sakurai Y, Kanda T, Takeuchi M (2014) Changes in subfoveal choroidal thickness associated with uveitis activity in patients with Behçet's disease. $\mathrm{Br} \mathrm{J}$ Ophthalmol 98(11):1508-1513

29. Onal S, Uludag G, Oray M, Mengi E, Herbort CP, Akman M, Metin MM, Koc Akbay A (2018) TugalTutkun I. quantitative analysis of structural alterations in the choroid of patients with active Behçet uveitis. Retina 38(4):828-840

30. Ahn SJ, Kim JH, Lee BR (2017 Jun) Choroidal change in acute anterior uveitis associated with human leukocyte antigen-B27. PLoS One 28(6):e0180109 12(

31. Basarir B, Celik U, Altan C, Celik NB (2018) Choroidal thickness changes determined by EDI-OCT on acute anterior uveitis in patients with HLA-B27-positive ankylosing spondylitis. Int Ophthalmol 
38(1):307-312

32. Kim M, Kim RY, Park YH (2019) Choroidal Vascularity Index and Choroidal Thickness in Human Leukocyte Antigen-B27-Associated Uveitis. Ocul Immunol Inflamm 27(8):1280-1287

33. da Silva FT, Sakata VM, Nakashima A, Hirata CE, Olivalves E, Takahashi WY, Costa RA, Yamamoto JH (2013) Enhanced depth imaging optical coherence tomography in long-standing Vogt-KoyanagiHarada disease. Br J Ophthalmol 97(1):70-74

34. Coskun E, Gurler B, Pehlivan Y, Kisacik B, Okumus S, Yayuspayı R, Ozcan E, Onat AM (2013) Enhanced depth imaging optical coherence tomography findings in Behçet disease. Ocul Immunol Inflamm 21(6):440-445

35. Liu S, Du L, Zhou Q, Zhang Q, Hu K, Qi J, Liang L, Zhou C, Kijlstra A, Yang P (2018) The Choroidal Vascularity Index Decreases and Choroidal Thickness Increases in Vogt-Koyanagi-Harada Disease Patients During a Recurrent Anterior Uveitis Attack. Ocul Immunol Inflamm 26(8):1237-1243

36. Ozer MD, Batur M, Tekin S, Seven E, Kebapci F (2020) Choroid vascularity index as a parameter for chronicity of Fuchs' uveitis syndrome. Int Ophthalmol 40(6):1429-1437

37. Hayreh SS. Blood supply of the optic nerve head. Ophthalmologica. 1996;210(5):285 - 95. doi: 10.1159/000310727. PMID: 8878212

38. Tugal-Tutkun I, Güney-Tefekli E, Kamaci-Duman F et al (2009) A cross-sectional and longitudinal study of Fuchs uveitis syndrome in Turkish patients. Am J Ophthalmol 148:510-515

39. Goker YS, Ozdal PC, Erol YO, KızIltoprak H, Karatepe MS (2019) Evaluation of radial peripapillary capillary density in patients with Fuchs uveitis syndrome. Graefes Arch Clin Exp Ophthalmol 257(12):2735-2742

40. Esfandiari H, Loewen NA, Hassanpour K, Fatourechi A, Yazdani S, Wang C, Yaseri M, Pakravan M. Fuchs heterochromic iridocyclitis-associated glaucoma: a retrospective comparison of primary Ahmed glaucoma valve implantation and trabeculectomy with mitomycin C. F1000Res. 2018;22;7:876

\section{Figures}




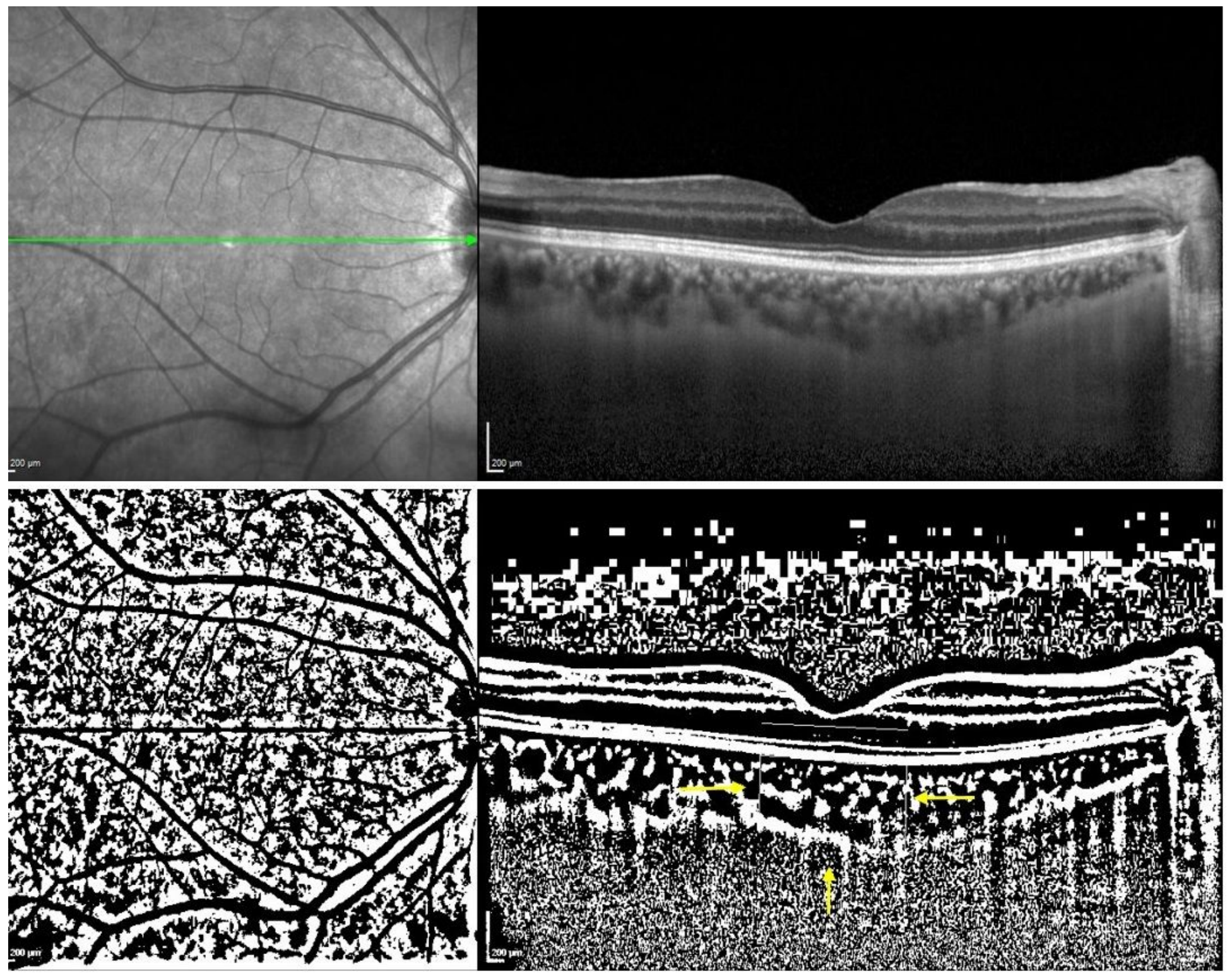

Figure 1

Illustration of submacular choroidal vascularity index measurement using Image J software

(https://imagej.net). The horizontal EDI-OCT scans were binarized using Niblack method of autolocal threshold tool. A $1500 \mu \mathrm{m}$ width line was drawn and circumscribed choroidal sectors (yellow arrows) were selected using the polygon tool. The upper border was marked at the retinal pigment epithelium and the lower border area was below the line of light pixels at the choroid scleral junction. 


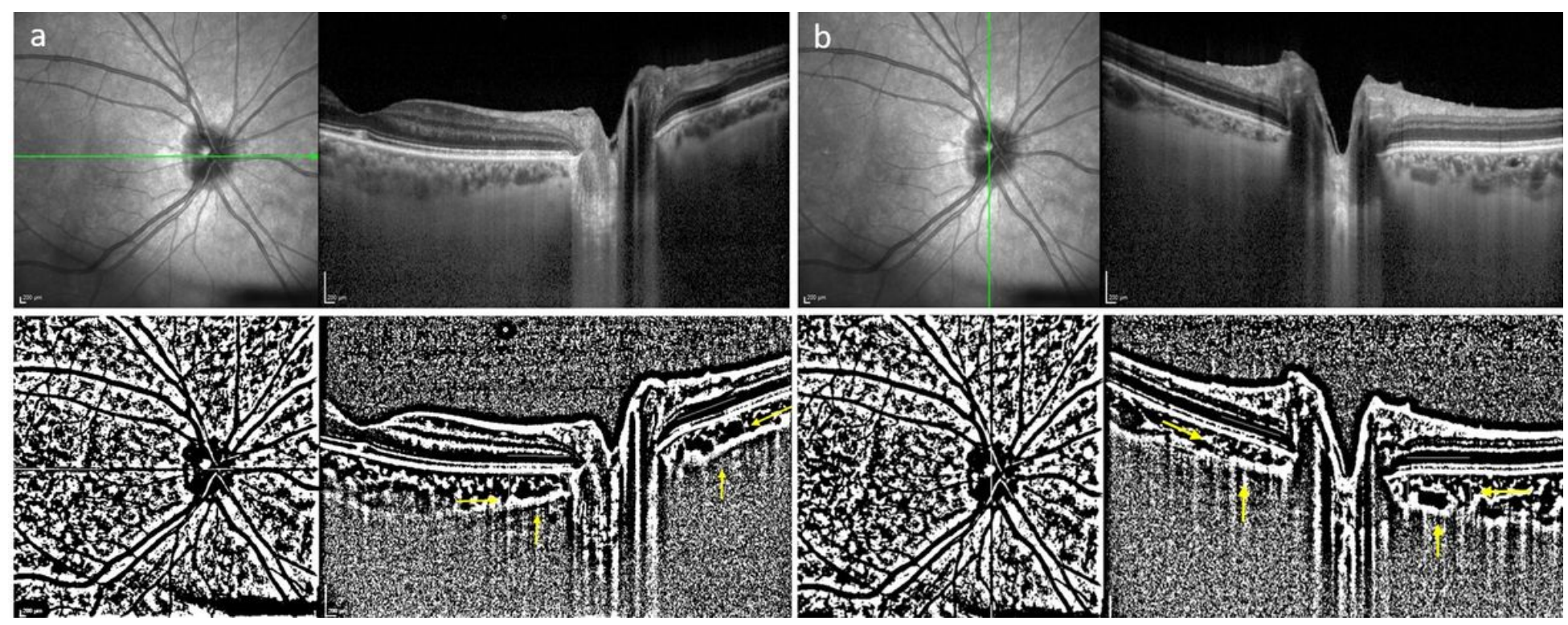

Figure 2

Illustration of peripapillary choroidal vascularity index measurement using ImageJ software (https://imagej.net) a) horizontal (temporal and nasal) and b) vertical (superior and inferior)peripapillary EDI-OCT scans centered on the optic nerve head.The scans were binarized using Niblack method of autolocal threshold tool. A $1000 \mu \mathrm{m}$ width line was drawnand circumscribed peripapillary choroidal sectors (yellow arrows) were selected using the polygon tool. The upper border was marked at the retinal pigment epithelium and the lower border area was below the line of light pixels at the choroid scleral junction. 